\title{
O TRABALHO PEDAGÓGICO PARA ALUNOS PÚBLICO-ALVO DA EDUCAÇÃO ESPECIAL: INVESTIGANDO A INCLUSÃO NA EDUCAÇÃO INFANTIL
}

\author{
PEDAGOGICAL WORK FOR STUDENTS WHO ARE THE TARGET- \\ AUDIENCE OF SPECIAL EDUCATION: INVESTIGATING INCLUSION IN \\ CHILDREN'S EDUCATION
}

Tamiris Aparecida FACHINETTI ${ }^{\mathrm{i}}$ Beatriz A. Barboza do NASCIMENTO ${ }^{\text {ii }}$ Cláudia Regina Mosca GIROTO ${ }^{\mathrm{iii}}$

RESUMO: A atuação do professor da Educação Infantil com alunos público-alvo da Educação Especial tem assumido relevância no contexto educacional inclusivo, uma vez que a mediação desse professor, bem como a adoção de metodologias compatíveis com tal perspectiva, nessa etapa educacional, é preponderante para a garantia de acesso, permanência e participação desses alunos na escola, desde o início de seu processo de escolarização. Subsidiado por tais ideias, o presente trabalho teve por objetivo investigar como se dá o trabalho pedagógico desse professor, em classe regular, na Educação Infantil, para alunos público-alvo da Educação Especial, com vistas à apropriação do currículo, por parte desse público. Foram realizadas observações em salas de aula de quatro professoras que atuavam em classes de educação infantil, que contavam com alunos público-alvo da Educação Especial matriculados, de quatro escolas de dois municípios do interior paulista. Os resultados desse estudo demonstraram de que forma esses alunos foram incluídos nas atividades desenvolvidas e de que modo as professoras utilizavam sua prática docente para atender a todos os alunos e, particularmente, aos que se encontravam caracterizados como público-alvo da Educação Especial.

PALAVRAS-CHAVE: Educação infantil. Educação inclusiva. Formação de professores. Trabalho docente. Público-alvo da educação especial.

ABSTRACT: The performance of the teacher of childhood education with the students of special education target public has assumed relevance in the inclusive educational context, since the mediation of this teacher, as well as the adoption of methodologies consistent with this perspective, this educational stage is crucial for ensuring access, retention and participation of those students in school from the beginning of their schooling process. Subsidized by such ideas, this study aimed to investigate, in the regular classroom, how is the teacher's practices in the children's education, to the students of special education target public with a view to the appropriation of the curriculum by that public. Observations were carried out in four classrooms of teachers that were acting in childhood education classes, which were counting with students of special education target public registered in in four schools in two cities in the countryside of Sao Paulo. The results of this study demonstrated how these students were included in the developed activities, as well how the teachers used their teaching practice to attend to all students, and particularly those who found themselves characterized as special education target public.

KEYWORDS: Childhood education. Inclusive education. Teacher's training. Teaching practices. Special education target public. 


\section{Introdução}

A Educação Infantil é uma importante etapa da educação, porque contribui de forma significativa para o desenvolvimento físico, psicológico, intelectual e social da criança (BRASIL 2009a).

Paniagua e Palacios (2007) enfatizam que a Educação Infantil deve proporcionar experiências e interações com o mundo social e físico, de forma ajustada às sucessíveis idades que abrange e seguindo os princípios pedagógicos, de acordo com o desenvolvimento de cada criança.

O reconhecimento da educação em creches e pré-escolas, como direito da criança e dever do Estado, veio depois de muitas lutas e consta como um direito a partir da Constituição Federal de 1988 (BRASIL, 1988), embora ainda não tivesse caráter obrigatório (OLIVEIRA, 2002). Porém, com a Lei 12.796/2013 (BRASIL, 2013), a educação básica passou a alcançar a faixa etária dos quatro aos dezessete anos, tornando assim a pré-escola etapa obrigatória do ensino.

A Lei de Diretrizes e Bases da Educação Nacional (BRASIL, 1996) destaca que o sistema educacional assegurará aos alunos com necessidades educacionais especiais currículos, métodos, recursos e organizações pertinentes para responder as suas necessidades. Por sua vez, a Política Nacional de Educação Especial na Perspectiva da Educação Inclusiva (BRASIL, 2008) aponta que a Educação Especial é uma modalidade de ensino que perpassa todos os níveis de ensino, com a oferta de atendimento educacional especializado (AEE), por meio da disponibilização dos recursos e serviços destinados ao suporte ao processo de escolarização de alunos com deficiências, transtornos globais do desenvolvimento (TGD) e altas habilidades/superdotação, que constituem o público-alvo da Educação Especial.

Neste sentido, todas as crianças têm assegurado, pelas políticas educacionais vigentes, o direito a educação pública e de qualidade. Porém, surgem diversos entraves para a materialização desse direito, particularmente no que diz respeito aos alunos público-alvo da Educação Especial, tais como: precarização da formação docente para a atuação na perspectiva da educação inclusiva; falta de infraestrutura dos sistemas educacionais e das escolas em geral que, frequentemente, encontram-se permeadas por diferentes barreiras ao acesso, permanência e participação desse público nas diferentes práticas educacionais e que, portanto, encontram-se despreparadas para atender toda a diversidade de alunos; diversidade sóciopolíticoeconômica das diferentes regiões do 
país, em decorrência de fatores circunstanciais e contingenciais que corroboram para o distanciamento entre as disposições legais e sua concretização nos diferentes contextos educacionais, entre outros.

Faz-se necessário, então, conhecer um pouco da história da Educação Infantil em nosso país, bem como a trajetória da Educação Especial para entender como essa modalidade de ensino sofreu mudanças até chegar ao paradigma atual.

\section{Breve histórico da Educação Infantil no Brasil}

Até meados do século XIX, no Brasil, não existia instituições dedicadas ao atendimento às crianças, como creches ou parques infantis. A maior parte da população, nessa época, residia na zona rural e as crianças órfãs ou abandonadas eram cuidadas pelas famílias dos fazendeiros. Na zona urbana, os bebês eram abandonados nas "rodas de expostos" que ficavam em hospitais para que, quando girasse, o bebê fosse colocado dentro, sem que a identidade de quem o deixou fosse revelada (OLIVEIRA, 2002).

Após a abolição da escravatura, acentua-se a migração para a zona urbana e começa-se a discutir as concepções elaboradas na Europa sobre a Educação Infantil:

o projeto social de construção de uma nação moderna, parte do ideário liberal presente no final do século XIX, reunia condições para que fossem assimilados, pelas elites do país, os preceitos educacionais do Movimento das Escolas Novas, elaborados no centro das transformações sociais ocorridas na Europa e trazidos ao Brasil pela influência americana e europeia. O jardim-de-infância, um desses 'produtos' estrangeiros, foi recebido com entusiasmo por alguns setores sociais. (OLIVEIRA, 2002, p. 92).

Muitos políticos da época criticavam o jardim-de-infância por não acreditarem que trariam vantagens para o desenvolvimento da criança. Entendiam esses jardins como "locais de mera guarda". Em 1875 foi criado, no Rio de Janeiro, o primeiro jardim-de-infância, porém, era uma instituição privada. Alguns anos depois, surgiram os jardins-de-infância públicos, mas o atendimento era voltado para as crianças das classes mais favorecidas.

Somente com o processo de urbanização brasileira e, consequentemente, com a industrialização, surgiu a necessidade de atendimento às crianças, principalmente com o intuito de proteger os filhos das mães que trabalhavam, pois com a chegada das fábricas 
houve uma mudança na estrutura da família tradicional brasileira, e as mulheres saíram de casa para trabalhar nas indústrias. Porém, a Educação Infantil constituía-se, nessa ocasião, de um caráter puramente assistencialista.

Na década de 1970 houve um processo de municipalização da educação préescolar pública, incentivada pelo aumento da demanda de alunos, conforme esclarece Oliveira (2002, p. 110):

O aumento da demanda por pré-escola incentivou, na década de 70, o processo de municipalização da educação pré-escolar pública, com a diminuição de vagas nas redes estaduais de ensino e sua ampliação nas redes municipais, política intensificada com a aprovação da Emenda Calmon à Constituição Nacional (1982), que vinculava um percentual mínimo de $25 \%$ das receitas municipais a gastos com o ensino em geral. Em 1972 já havia 460 mil matrículas na pré-escola em todo país.

A Resolução $n^{\circ}$ 5, de dezembro de 2009 (BRASIL, 2009b), fixa as diretrizes curriculares nacionais para essa modalidade educacional e estabelece o dever do Estado em garantir a oferta da Educação Infantil pública, gratuita e de qualidade.

Assim, acabou mudando o conceito que se tinha sobre a infância. Segundo Kramer (2003, p.19), no período feudal a criança exercia um papel "de adulto". Atualmente ela tem sido compreendida como um ser que necessita de cuidados e escolarização para atuar no futuro.

\begin{abstract}
A ideia de infância [...] aparece com a sociedade capitalista, urbanoindustrial, na medida em que mudam a sua inserção e o papel social da criança na comunidade. Se, na sociedade feudal, a criança exercia um papel produtivo direto ('de adulto') assim que ultrapassava o período de alta mortalidade, na sociedade burguesa ela passa a ser alguém que precisa ser cuidada, escolarizada e preparada para uma função futura. Este conceito de infância é, pois, determinado historicamente pela modificação das formas de organização da sociedade.
\end{abstract}

\title{
A Educação Especial na perspectiva da educação inclusiva
}

A partir da década de 1990, o Brasil, seguindo as políticas internacionais, passou a adotar medidas para transformar o sistema de ensino em um sistema que atendesse a todos. Tendo como grande marco a Declaração de Jomtien, em 1990 (UNESCO, 1990), 
e de Salamanca, em 1994 (BRASIL, 1994), que garantem a educação no ensino regular a todos os grupos minoritários, as normativas legais brasileiras sofreram mudanças transformando os sistemas educacionais de forma rápida e obrigatória.

A Educação Especial, passando pelos paradigmas de institucionalização e de serviço, a partir das proposições políticas, agora encontra-se organizada sob os princípios do paradigma de suporte, sob o qual essa modalidade de ensino deve dar suporte ao seu público-alvo, para que esse alcance sucesso no ensino regular, por meio da garantia de educação de qualidade. Dessa forma, a Educação Especial tem caráter complementar ao ensino comum e não mais substitutivo, perpassando todos os níveis de ensino (BRASIL, 2008).

Como essa modalidade assumiu o caráter de suporte, o papel de levar o aluno à apropriação, na sala regular, do processo de ensino e de aprendizagem, é do professor da sala comum. Para tal, as políticas educacionais vigentes preconizam a atuação colaborativa, especialmente com o professor especialista, responsável pelo AEE, ofertado nas salas de recursos multifuncionais. O AEE caracteriza-se como um serviço da Educação Especial e deve ser oferecido sob a condição de suporte aos alunos público-alvo da Educação Especial, de forma articulada com o ensino regular, orientando para o atendimento às necessidades educacionais especiais desse público (BRASIL, 2009c).

$\mathrm{O}$ art. $3^{\circ}$, do Decreto $\mathrm{n}^{\mathrm{o}}$ 7611/11 (BRASIL, 2011), indica os objetivos do atendimento educacional especializado, sendo: promover acesso, participação e aprendizagem no ensino regular e garantir os serviços de apoio especializados para suprir as necessidades individuais dos alunos; promover a transversalidade das atuações da Educação Especial no ensino regular; promover o desenvolvimento de recursos pedagógicos que extingam as barreiras no processo de ensino e aprendizagem e assegurar condições para a continuidade de estudos nos níveis subsequentes, etapas e modalidades de ensino.

Está claro que a proposta da educação inclusiva é oferecer um ensino de qualidade a todos de forma equânime. Percebe-se que a sociedade, ainda que em passos lentos, tem buscado atender as demandas de pessoas com necessidades especiais.

Sob a compreensão de que tais demandas precisam ser atendidas, em prol da educação de qualidade, o ensino, no Brasil, precisa ultrapassar metas como a de acesso e garantia de vagas e atingir possibilidades reais de desenvolvimento dos indivíduos com necessidades educacionais especiais, de forma que a escola seja inclusiva e ofereça 
condições de igualdade no acesso às mais diferentes oportunidades disponíveis nos diferentes contextos educacionais.

No que concerne especificamente à inclusão de alunos público-alvo da Educação Especial na Educação Infantil, Vitta, Silva e Zaniolo (2016, p.24) apontam o descompasso entre as políticas educacionais vigentes e a concretização de suas disposições legais, o que evidencia o distanciamento entre "[...] o que é projetado idealmente e o que acontece, o que é planejado e o que é vivido". Esses autores afirmam que "[...] é preciso que o atendimento à criança de zero a três anos deixe a dimensão assistencialista, paliativa de problemas sociais estruturais maiores e seja considerada como um direito social de todas as crianças", uma vez que consideram que a perspectiva assistencialista ainda persiste, em muitos casos, nessa etapa da educação básica.

Diante desse contexto, esse estudo teve por objetivo investigar como se dá o trabalho pedagógico do professor em classe regular, na Educação Infantil, para alunos público-alvo da Educação Especial, com vistas à apropriação do currículo, por parte desse público.

\section{Metodologia}

A abordagem qualitativa subsidiou a pesquisa em questão, pois sob essa abordagem, as questões de pesquisa são elaboradas objetivando investigar os fenômenos num contexto natural, a partir do ponto de vista dos sujeitos da investigação (BOGDAN; BIKLEN, 1994).

A pesquisa foi realizada em quatro escolas municipais de Educação Infantil, de dois municípios do interior paulista, doravante denominados de município 1 e município 2. Três escolas pertenciam ao município 1 e uma ao município 2. Tais escolas são aqui denominadas, respectivamente, de escolas A, B, C e D, a fim de preservar suas identidades.

Conforme os dados disponibilizados no Quadro 1, é possível verificar o perfil dos alunos público-alvo da Educação Especial correlacionado com as respectivas escolas nas quais esses alunos encontram-se matriculados: 
Quadro 1. Perfil das escolas participantes da pesquisa.

\begin{tabular}{|c|c|c|c|c|}
\hline Escolas & $\mathbf{A}$ & B & C & D \\
\hline $\begin{array}{l}\text { Nível escolar } \\
\text { observado }\end{array}$ & Fase V & Fase V & Fase I & Fase VI \\
\hline $\begin{array}{l}\text { Número de } \\
\text { alunos na sala }\end{array}$ & 25 & 20 & 19 & 22 \\
\hline $\begin{array}{l}\text { Diagnóstico } \\
\text { dos alunos } \\
\text { público-alvo } \\
\text { da Educação } \\
\text { Especial }\end{array}$ & $\begin{array}{l}\text { Aluno P } \\
\text { Deficiência Física } \\
\text { (Comprometimento } \\
\text { nos membros } \\
\text { inferiores) }\end{array}$ & $\begin{array}{l}\text { Aluno J: } \\
\text { Deficiência } \\
\text { Intelectual } \\
\text { (e possível } \\
\text { diagnóstico de } \\
\text { transtorno do } \\
\text { espectro } \\
\text { autista) }\end{array}$ & $\begin{array}{l}\text { Aluna R: } \\
\text { Deficiência } \\
\text { Física } \\
\text { (Paralisia } \\
\text { cerebral) } \\
\\
\text { Aluna A: } \\
\text { Deficiência } \\
\text { Intelectual } \\
\text { (Síndrome de } \\
\text { Kabuki) }\end{array}$ & $\begin{array}{l}\text { Aluno N: } \\
\text { Deficiência } \\
\text { Intelectual } \\
\text { (Síndrome de } \\
\text { Down) }\end{array}$ \\
\hline Município & 1 & 1 & 2 & 1 \\
\hline
\end{tabular}

Fonte: Dados da pesquisa

Dessas quatro escolas, participaram voluntariamente da pesquisa, após assinatura do termo de consentimento livre e esclarecido, quatro professoras da Educação Infantil, sendo uma de cada escola, que atuam em classe comum com alunos público-alvo da Educação Especial matriculados em tais classes.

Para fins de apresentação e discussão dos resultados considerados para a análise, tais professoras foram aqui identificadas pela letra $\mathrm{P}$, seguida pela letra de identificação da escola (PA, PB, PC e PB). O Quadro 2, apresentado a seguir, compreende dados acerca do perfil dos professores participantes, no que diz respeito à formação docente (inicial e continuada):

Quadro 2. Perfil dos professores participantes da pesquisa.

\begin{tabular}{|l|c|c|c|c|}
\hline Professores & PA & PB & PC & PD \\
\hline Formação Inicial & $\begin{array}{c}\text { Magistério e } \\
\text { pedagogia }\end{array}$ & Pedagogia & $\begin{array}{c}\text { Pedagogia e } \\
\text { Terapia } \\
\text { Ocupacional }\end{array}$ & (não informado) \\
\hline $\begin{array}{l}\text { Formação } \\
\text { Continuada }\end{array}$ & $\begin{array}{c}\text { Pós-graduação em } \\
\text { Alfabetização }\end{array}$ & $\begin{array}{c}\text { Especialização em } \\
\text { Educação Especial } \\
\text { e Psicopedagogia }\end{array}$ & Não possui & (não informado) \\
\hline
\end{tabular}

Fonte: Dados da pesquisa 
A coleta de dados ocorreu por meio de um roteiro de observação, que compreendia o registro de informações sobre os recursos e estratégias utilizadas com os alunos público-alvo da Educação Especial matriculados nessas quatro salas de aula. As observações foram realizadas duas vezes por semana, em um semestre, durante todo o período de estágio de alunas do curso de Licenciatura em Educação Especial, da Universidade Federal de São Carlos (UFSCar).

A análise de dados se deu por meio da elaboração de categorias, frente a ação das professoras e as respostas dos alunos. Foi realizada a descrição dos momentos observados, atentando-se para os recursos e materiais utilizados por elas e, principalmente, suas estratégias.

Assim, a partir das leituras dos registros das referidas sessões de observação realizadas, foram eleitas cinco categorias de análise, conforme seguem:

- Categoria 1: Perfil das salas de aula regulares, que compreendeu informações sobre a organização do ambiente;

- Categoria 2: Relação professor/aluno que abordou como o professor se posicionou frente aos alunos público-alvo da Educação Especial;

- Categoria 3: Planejamento e organização, que descreveu as rotinas na Educação Infantil;

- Categoria 4: Prática docente em relação aos alunos público-alvo da Educação Especial, que compreendeu dados sobre e como as atividades em sala são abordadas, no que tange os alunos com deficiências, TGDs, altas habilidades/superdotação;

- Categoria 5: O brincar no contexto escolar, que teve por finalidade subsidiar a reflexão sobre a finalidade desse nível de ensino.

\section{Resultados e discussão}

Os resultados encontrados nessa pesquisa subsidiaram as reflexões diante das diversas situações observadas, cuja análise foi embasada pela literatura compulsada. Para melhor compreensão, os resultados são aqui apresentados e discutidos em conformidade com as cinco categorias elencadas anteriormente. 


\section{Perfil das salas regulares}

Cabe ao adulto a organização do ambiente, de modo a torná-lo um local propício para a interação da criança com o meio e também com seus pares. É preciso considerar a qualidade da mediação do adulto tanto nas atividades e brincadeiras livres, como instrumento de estimulação ou condição para a aprendizagem e desenvolvimento das crianças (CÓRIA-SABINI; LUCENA, 2009). Os alunos público-alvo da Educação Especial devem estar inseridos em um ambiente propício a uma aprendizagem ativa. Essa aprendizagem significa que o ambiente deve ser organizado, de modo que a criança seja motivada a agir e verificar o resultado da sua ação no local em que está inserida (NUNES, 2001).

Para entender a organização do ambiente da sala de aula da escola A é importante esclarecer as dificuldades do aluno $\mathrm{P}$ que se encontrava incluído nessa sala. A deficiência física desse aluno acomete os membros inferiores, com consequente comprometimento de seu desenvolvimento motor. Em razão desse comprometimento, $\mathrm{P}$ não desenvolveu habilidades motoras grosseiras, como caminhar sozinho ou correr. Dessa forma, ele se locomovia pela sala arrastando-se ou com auxílio da professora, que o apoiava segurando suas mãos.

Frente a essas características, a organização do ambiente da sala encontrava-se disposta de acordo com as necessidades do aluno para a facilitação da locomoção do mesmo. Assim, as mesas e cadeiras ficavam acomodadas nas laterais da sala para o meio ficar livre e facilitar a locomoção desse aluno até a parte da frente da sala, em que ficava a lousa, os armários com brinquedos e a mesa da professora. Tal organização refletia a iniciativa da professora de incluir o aluno na sala.

Em relação aos recursos presentes nessa sala, foi possível observar: varal para colocar as atividades realizadas pelos alunos; varal com número e o alfabeto; prateleira com livros e gibis infantis, além de alguns cartazes.

A sala de aula da escola $\mathrm{B}$, em relação ao espaço físico e recursos, era composta por amplo espaço com varal para colocar as atividades realizadas pelos alunos; balde e prateleira com brinquedos; dois armários, um para a professora de cada turno; lousa; calendário na parede; mesas e cadeiras; e prateleira com os livros e gibis infantis.

No que diz respeito a escola $\mathrm{C}$, as mesas encontravam-se espalhadas na sala, comportando três ou quatro alunos. Esta estrutura proporcionava aos alunos que trocassem informações, bem como favorecia o acesso visual de todos. Ainda continha 
dois armários (um da professora da manhã e outro da tarde), uma lousa e caixas de brinquedos de encaixe.

$\mathrm{Na}$ escola $\mathrm{D}$, a sala compreendia uma mesa da professora, dois armários, um para a professora que atuava na sala no período da manhã e outro para a professora que atuava no período da tarde. Havia uma lousa e anexado às paredes o "trem do alfabeto", com todas as letras, e o "trem dos números". Além disso, a sala de aula tinha um espelho grande, uma estante com gibis, um calendário, a lista de chamada com os nomes dos alunos e um varal de atividades dos alunos do período da manhã. Também havia na sala três baldes de brinquedos, uma prateleira com brinquedos que estimulavam a coordenação motora e o reconhecimento de letras e dos números. Possuía seis mesas quadradas pequenas para os alunos, que se organizavam em quatro alunos em cada mesa.

Percebe-se que, mesmo sendo escolas diferentes, a caracterização das salas é bem similar, de forma a propiciar o contato entre todos, bem como diminuir as barreiras físicas.

\section{Relação professor/aluno}

Na Educação Infantil os funcionários e, principalmente, os professores devem estabelecer um vínculo positivo e equilibrado com as crianças. É importante que o professor seja sensível às necessidades de cada criança, demonstrando afeto (PANIAGUA; PALACIOS, 2007).

O papel do professor na Educação Infantil caracteriza-se em facilitador das interações e socializações que a troca entre os pares proporciona (BRASIL, 2009a), pois é na fase pré-escolar que os alunos iniciam suas primeiras amizades e preferências por companheiros. Nesse momento, eles começam a emitir comportamentos positivos, maior generosidade e afeto (BEE, 2008).

A esse respeito, a professora A demonstrou um aspecto facilitador, observado em suas atitudes com os alunos. A mesma oferecia um clima afetivo que criava condições de harmonia e bem-estar na sala de aula, o que favorecia certo controle sob alguns alunos que manifestavam problemas comportamentais. Sua relação com o aluno $\mathrm{P}$ era a mesma que estabelecia com os demais alunos, a única diferença é que ela 
sempre fazia com que o aluno $\mathrm{P}$ fosse o primeiro nas filas, pois precisava auxiliá-lo na locomoção, e os demais alunos não questionavam isso.

A professora $\mathrm{B}$ tratava todos os alunos da mesma forma, mas apresentava uma postura um pouco mais rígida perante o aluno $\mathrm{J}$, porque o mesmo apresentava sérios problemas de comportamento. Foi possível notar que PB sentia prazer em trabalhar com os alunos e sempre buscava atividades em grupo que favorecesse toda a sala.

A professora $\mathrm{C}$ também não fazia diferenciação quanto ao conteúdo abordado com os demais alunos da sala. As adaptações só se referiam à alteração de estratégias de ensino que visassem o desenvolvimento pleno dos alunos público-alvo da Educação Especial, porém, em relação a aluna $\mathrm{R}$, essa tinha uma cuidadora que muitas vezes realizava as atividades por ela.

Em relação a professora $\mathrm{D}$, essa facilitava as atividades do aluno $\mathrm{N}$ e não forçava a sua participação nas atividades, tanto individuais quanto em grupo.

\section{Planejamento e organização das aulas}

Segundo Paniagua e Palacios (2007), geralmente a jornada na Educação Infantil começa com uma conversa em grupo, posteriormente o professor passa para atividades em mesas com material escolar que tendem a ser dirigidas e, após o término dessas atividades, é introduzida a hora da brincadeira, que pode ser desenvolvida de várias maneiras.

A PA utilizava, em sua prática pedagógica, diferentes atividades que favoreciam a alfabetização das crianças. Eram frequentemente realizadas, na sala, tarefas de ligar, copiar, relacionar, recortar e identificar. A leitura era muito estimulada e na sala encontravam-se expostos cartazes com receita de bolo ou com músicas. Segundo essa professora, esses cartazes serviam para motivar leitura, o que ela denominou de pseudoleitura.

Oliveira (2010) refere-se a essa forma de pseudoleitura como a que mais se aproxima da adivinhação, porque a criança identifica apenas algumas características visuais das palavras, sem demonstrar qualquer capacidade para codificá-la. Assim, a identificação automática da palavra se dá pela leitura global dela.

Foi possível constatar, com as observações, que a professora B utilizava atividades dirigidas. Essas atividades realizavam-se, em sua maioria, dentro de sala de 
aula e por meio de folhas impressas. A professora assumia o papel de auxiliar e mediava as situações de aprendizagem.

O professor assume um papel importante na mediação do processo de aprendizagem de alunos da Educação Infantil, na aquisição do conhecimento, como mediador, orientador e facilitador da aprendizagem. No que diz respeito a essa professora, a mesma sempre tentava relacionar atividades acadêmicas com as brincadeiras, então, por exemplo, quando ela desenvolveu uma atividade com receita de bolo, trabalhou no parque o faz de conta com o bolo por meio da areia e balde.

As aulas da professora $\mathrm{C}$ também eram baseadas em rotinas e todos os alunos já estavam habituados com essa dinâmica de funcionamento (oração, atividades de leitura, brincadeiras, músicas, recreio, parque, entre outros).

Na sala da professora $\mathrm{D}$, a rotina escolar era anexada na lousa e, na parede do refeitório, o cardápio do dia era elaborado com a utilização de imagens e palavras escritas. Toda sexta-feira, a partir das duas horas, os alunos se organizavam em filas para cantar o hino nacional.

Constatou-se que todas as professoras utilizavam rotina no dia a dia da sala de aula. Dessa forma, os alunos cantavam músicas infantis, brincavam com os brinquedos da sala e utilizavam livros de história. As atividades como filme, contação de história e uso de massinha de modelar eram frequentes, além das brincadeiras livres no parque de areia.

A esse respeito, Oliveira-Formosinho (2007) ressalta que a rotina deve ser planejada, porém, de forma flexível, devendo envolver o cuidado, o ensino e as especificidades imaginativas da criança. O conhecimento da sequência da rotina é também fator que favorece o desenvolvimento da autonomia.

De acordo com Chavier (2006) e Vitalino e Valente (2010), faz-se necessária a tomada de decisões e a criação de estratégias durante o próprio agir docente, para gerar possibilidades pedagógicas que atendam às necessidades que emergem no cotidiano da escola.

\section{Prática docente em relação aos alunos público-alvo da educação especial}

Giroto e Castro (2011) referem que a atuação do professor da Educação Infantil com alunos público-alvo da Educação Especial tem assumido relevância no contexto 
educacional inclusivo, uma vez que a mediação desse professor - bem como a adoção de metodologias compatíveis com tal perspectiva - nessa etapa educacional, é preponderante para a garantia de acesso, permanência e participação desses alunos na escola, desde o início de seu processo de escolarização.

$\mathrm{Na}$ Educação Infantil destaca-se que as práticas inclusivas devem acontecer o mais cedo possível, por meio da matrícula dos alunos nessa modalidade de ensino, pois os primeiros anos da infância são marcados pelo desenvolvimento e aprendizado global das crianças. Dessa forma, os ambientes em que essas crianças convivem são significativamente relevantes para a aquisição das habilidades (MENDES, 2010).

A professora A auxiliava o aluno $\mathrm{P}$ na locomoção até o parque e ao refeitório. Algumas vezes esse aluno tomava iniciativa de ir sozinho. Dessa forma, ele se arrastava no chão com impulso das mãos. No parque, quando o aluno queria ir ao balanço ou em outro brinquedo, ele pedia para a professora, que sempre se dispôs a auxiliá-lo. Na sala de aula, quando era o momento de brincar, o aluno pedia para a professora pegar algum brinquedo para ele. A professora escolhia aleatoriamente sem perguntar a preferência do aluno e esses brinquedos ficavam localizados em um armário próximo a lousa.

A professora $\mathrm{B}$ dava mais atenção ao aluno $\mathrm{J}$ no horário do lanche, porque o maior problema do aluno era no refeitório, onde ele apresentava problemas comportamentais. Supõe-se que esses comportamentos estivessem relacionados ao grande barulho nesse ambiente. Na sala, a professora fazia uso de estratégias tais como: o reforço positivo, por meio de elogios ao aluno $\mathrm{J}$ durante a execução da tarefa; oferecimento de dicas, quando o aluno apresentava maiores dificuldades; e realizava repetições quantas vezes fossem necessárias.

Segundo Falconi e Silva (2013), as estratégias tais como a de repetição, atenção aos comportamentos do aluno e trabalhar juntamente com o aluno são muito importantes para o desenvolvimento do mesmo. As estratégias foram utilizadas tanto com o aluno com deficiência, quanto com os demais, quando necessário.

A professora $\mathrm{C}$, no que diz respeito a aluna $\mathrm{R}$, não interagia muito com a criança, deixando-a aos cuidados de uma cuidadora, tanto nas atividades quanto nos horários de refeição. A aluna A, por sua vez, não apresentava dificuldades na realização das atividades, recebendo tratamento igual aos demais alunos, com auxílio da professora quando necessário.

Em relação a professora $\mathrm{D}$ e o aluno $\mathrm{N}$, a atenção voltada a ele estava relacionada mais ao desenvolvimento das atividades acadêmicas e da linguagem, do que 
à socialização. Muitas vezes, o aluno $\mathrm{N}$ não realizou as atividades propostas, ou pelo grau de dificuldade ou pelo desinteresse em atividades que eram desenvolvidas no caderno. Nas atividades realizadas fora da sala de aula ou utilizando os net books da escola o aluno $\mathrm{N}$ apresentava um bom desempenho. Porém, ele faltava muito, o que dificultava sua aprendizagem.

Tratando-se de alunos público-alvo da Educação Especial, a mediação do professor torna-se ainda mais importante. Uma pratica educativa inclusiva necessita que a mediação do professor respeite as necessidades da criança, pois ela requer, por exemplo, mais tempo para explorar as propriedades dos objetos. O professor deve atentar-se, portanto, para a variação das respostas, das atitudes e da maneira como a criança se compromete com a atividade proposta (NUNES 2001).

Ainda, há que se considerar a importância do papel do professor da Educação Infantil na materialização e sistematização de experiências de sucesso de inclusão desse público, tendo em vista que esse professor se depara com esses alunos no início do processo de escolarização dos mesmos.

A esse respeito, Giroto e Castro (2011) apontam que "[...] sob essa perspectiva da educação inclusiva, o professor da Educação Infantil tem um destaque especial quanto ao acolhimento da criança" e, particularmente, no que se refere ao público-alvo da Educação Especial, uma vez que tal público, ao encontrar-se em fase inicial do processo de escolarização, necessitará da mediação desse profissional frente às inúmeras barreiras que enfrentará na escola.

Dentre essas barreiras, destacam-se as atitudinais e metodológicas, intrinsecamente relacionadas à formação e atuação docente. Neste sentido, as diversas formas de mediação desse professor, em sala de aula, as estratégias de ensino, bem como os recursos utilizados assumem relevância para a concretização da inclusão educacional desses alunos.

Experiências positivas de inclusão, no âmbito da Educação Infantil, podem, ainda, fortalecer a adoção, por parte das escolas, como um todo, e dos professores, em sala de aula, de políticas institucionais que corroborem para a construção de escolas mais inclusivas, cujas ações encontram-se fortemente assentadas na atuação colaborativa e no compartilhamento da perspectiva de que todos encontram-se igualmente envolvidos e são corresponsáveis pelo processo de escolarização desses alunos: escola; gestão; professor generalista; professor especialista; família e alunos são, 
portanto, igualmente relevantes em tal processo (GIROTO; CASTRO, 2011; GIROTO; MILANEZ, 2013; MIRANDA et al, 2013).

\section{O brincar no contexto escolar}

O brincar é um instrumento de aprendizagem e parte do processo educativo. Os profissionais da educação entendem que o brincar é importante para o desenvolvimento. A crítica, entretanto, é se o educador deve dirigir a brincadeira (MOYLES, 2006).

Para Pereira (2005), a concepção do adulto sobre o brincar influencia diretamente a direção e o significado que ele dará para essa atividade enquanto educador.

A professora A utilizava do brincar livremente, de forma que não o condicionava a outra tarefa. Assim, a brincadeira livre assumiu um papel central no cotidiano dessa sala de aula e não uma troca, condicionada ao término das atividades propostas. A professora deixava os alunos escolherem algum brinquedo do armário e dava autonomia para que eles dirigissem as brincadeiras em grupos, nas mesas, no chão etc. Foi possível observar que idas ao parque de areia não eram frequentes, mas quando ocorriam eram atividades livres, nas quais os alunos brincavam muito de faz de conta, principalmente as meninas, como por exemplo fazendo bolo.

Os brinquedos trazem muitos benefícios para o desenvolvimento. A escolha dos materiais, por si próprios, possibilitam às crianças autonomia e o ato de recolhê-los cria bons hábitos de ordem e responsabilidade (PANIAGUA; PALACIOS, 2007).

A professora B tinha uma maior frequência no parque de areia, no entanto as atividades eram mais dirigidas, uma vez que incentivava os alunos a brincarem em grupos, a utilizar os baldes, sempre perguntava o que eles estavam fazendo e até chegava a propor algumas brincadeiras de faz de conta. Constatou-se que essa professora ficava sempre atenta ao aluno J, para ele não jogar areia nas outras crianças.

A professora $\mathrm{C}$, de segunda a quarta-feira, quando havia um tempo livre na sala, deixava os alunos brincarem com jogos de encaixe. Tinha também o dia fixo das crianças irem ao parque e, toda sexta-feira, elas podiam levar seu brinquedo favorito para a escola, além de terem um tempo livre para brincar no pátio. 
A PD não mediava às relações entre os alunos durante as brincadeiras, apenas chamava a atenção dos alunos em situação de conflito (uso do parque, de massinha de modelar ou de peças de encaixe).

Para Mendes (2010), as ações dos professores são essenciais para o sucesso ou não da inclusão dos alunos público-alvo da Educação Especial na escola e, especificamente, na turma, pois este servirá de modelo e mediador das relações positivas na aceitação do aluno com deficiência pelos demais alunos da sala.

Paniagua e Palacios (2007) esclarecem que o valor para a aprendizagem e o equilíbrio pessoal da brincadeira na infância é reconhecido como um ponto de vista evolutivo, pois através do brincar a criança explora, descobre, consolida e se diverte. A brincadeira proporciona um desenvolvimento cognitivo e pessoal de forma livre que facilita a aprendizagem e o desenvolvimento das crianças.

Foi possível notar que o brincar encontra-se bastante presente na Educação Infantil, porém, com grande frequência ainda tem sido caracterizado como um preenchimento de tempo livre, não recebendo uma atenção especial do professor.

\section{Conclusões}

A dicotomia entre o cuidar e o educar está muito presente na prática dos profissionais da Educação Infantil.

Diante da história da Educação Infantil, percebe-se uma profunda ligação do atendimento às crianças com o assistencialismo, uma vez que a função professor muitas vezes confunde-se com a função materna, mas não há como negar o cuidado marcante dos profissionais que atuam com crianças de zero a cinco anos, apesar de isso ser conflituoso para alguns profissionais.

A Educação Infantil constitui-se numa modalidade educacional fundamental para o desenvolvimento e aquisição de habilidades em diferentes áreas do desenvolvimento da criança. Por esse pressuposto, a inclusão dos alunos público-alvo da Educação Especial, na Educação Infantil, torna-se muito importante para o processo de aprendizado desses alunos. Para tanto, ajustes metodológicos fazem-se necessários nesse contexto educacional para a proposição de respostas às demandas educacionais desse público, nessa faixa etária. 
Esses ajustes metodológicos puderam ser observados na sala da professora A, que adequou a disposição do mobiliário para facilitar a acessibilidade física desse aluno nesse ambiente. Estratégias como as utilizadas pela professora B, que ofereceu mais atenção em momentos em que o aluno $\mathbf{J}$ demonstrou maior agitação, ou nos em que reforçou o bom comportamento desse aluno caracterizaram iniciativas que facilitaram os processos de ensino e aprendizagem dos alunos público-alvo da Educação Especial. Semelhantemente, a professora $\mathrm{D}$ também apresentou iniciativas que favoreceram a permanência da aluna em sala de aula, a exemplo de quando sentava com sua aluna e a ajudava nas atividades nas quais apresentava dificuldades. Porém, o mesmo não ocorreu com a professora $\mathrm{C}$, uma vez que sua aluna permanecia junto da cuidadora, com pouca ou nenhuma mediação dessa professora nas situações de aprendizagem. Entretanto, em nenhuma dessas salas houve exclusão desses, por parte dos demais alunos.

As atividades lúdicas frequentemente foram adotadas no cotidiano das aulas e isso é uma pratica educativa indispensável na educação infantil, porque o brincar é importante para o favorecimento da construção do conhecimento. O papel do adulto é fundamental quando interfere, promove ou propõe a brincadeira, ou seja, atua na mediação do brincar, pois é ele quem introduzirá a criança nesse contexto e favorecerá sua inserção no meio cultural.

As experiências vivenciadas por essas professoras com alunos público-alvo da Educação Especial refletem que a construção cotidiana da educação inclusiva jamais terá fórmulas cujos resultados estejam previstos, portanto, faz-se necessária uma reflexão constante, por parte dos profissionais da Educação Infantil, sobre as práticas pedagógicas inclusivas nessa etapa do processo de escolarização desse público. Tal reflexão constitui-se num desafio que se impõe aos profissionais da Educação Infantil, em prol de uma formação e atuação docente condizentes com as demandas educacionais desses alunos e com a busca pela garantia de educação de qualidade.

\section{Referências}

BRASIL. Constituição da República Federativa do Brasil. Disponível em: <http://www.planalto.gov.br/ccivil_03/Constituicao/Constituicao.htm>. Acesso em: 14 maio 2016. 
Lei 9.394/96, de 20 de dezembro de 1996. Estabelece as diretrizes e bases da educação nacional. Diário Oficial da República Federativa do Brasil. Brasília, 1996. Disponível em: <http://www.planalto.gov.br/ccivil_03/Leis/L9394.htm>. Acesso em 14 set. 2015.

\section{Política Nacional de Educação Especial na Perspectiva da Educação} Inclusiva. Brasília: MEC/SEESP, 2008.

Subsídios para diretrizes curriculares nacionais para a educação básica. Brasília: Ministério da Educação, 2009a. p. 15-41.

Resolução No 5, de 17 de dezembro de 2009. Diretrizes Curriculares Nacionais para a Educação Infantil. Brasília: MEC, 2009b.

Resolução no 4/2009, de 02 de outubro de 2009. Disponível em: <http://portal.mec.gov.br/dmdocuments/rceb004_09.pdf〉. Acesso em: 28 jun 2016.

Decreto no 7.611, de 17 de novembro 2011. Dispõe sobre a Educação Especial, o Atendimento Educacional Especializado e dá outras providências. Disponível em: < http://portalsme.prefeitura.sp.gov.br/Documentos/OrganizaEscolar2012/OrganizaEscola r2012.pdf>. Acesso em: 02 out. 2014.

Lei $\mathrm{n}^{\circ}$ 12.796, de 4 de abril de 2013. Altera a Lei no 9.394, de 20 de dezembro de 1996, que estabelece as diretrizes e bases da educação nacional, para dispor sobre a formação dos profissionais da educação e dar outras providências. Diário Oficial da República Federativa do Brasil. Brasília, 2013. Disponível em <http://www.planalto.gov.br/ccivil_03/_ato2011-2014/2013/lei/112796.htm>. Acesso em: 21 set. 2015

BOGDAN, R.; BIKLEN, S. Investigação qualitativa em educação: uma introdução à teoria e aos métodos. Porto: Porto Editora, 1994.

BEE, H. A criança em desenvolvimento. Porto Alegre: Artmed, 9 ed., 2008.

CHAVIER, M. R. As contribuições da reflexividade na diversidade - Um caminho para inclusão. Inter-Ação: Revista da Faculdade de Educação, Goiana, UFG, v.31 n2, p. 209-217, 2006.

CÓRIA-SABINI, M. A.; LUCENA, R. F. Desenvolvimento e aprendizagem em situação escolar. In: CÓRIA-SABINI, M. A.; LUCENA, R. F. (Orgs). Jogos e brincadeiras na educação infantil. Campinas: Papirus, 2009.

FALCONI, E. R. M.; SILVA, N. A. S. Estratégias de trabalho para alunos com deficiência intelectual-AEE. Disponível em: $<$ https://especialdeadamantina.files.wordpress.com/2014/05/estratc3a9gias-de-trabalhopara-alunos-com-di.pdf>. Acesso em: 28 jul. 2016.

GIROTO, C. R. M.; CASTRO, R. M. A formação de professores para a educação inclusiva: alguns aspectos de um trabalho colaborativo entre pesquisadores $\mathrm{e}$ professores da Educação Infantil. In: Revista de Educação Especial de Santa Maria, v. 24, p. 441-452, 2011. 
GIROTO, C. R. M.; MILANEZ, S. G. C. La formación del profesorado de apoyos educativos especializados: ¿qué ha cambiado en la práctica docente especializada en el escenario educativo de Brasil. In: HEREDERO, E. S.; GIROTO, C. R. M.; MARTINS, S. E. S. O. (Org.). La formación del profesorado para la atención a la diversidad en Brasil y España. 1ed. Alcalá de Henares: Universidad de Alcalá, 2013.

KRAMER, S. A política do pré-escolar no Brasil: a arte do disfarce. São Paulo: Cortez. 7 ed.; 2003.

MIRANDA, M. J. C. Inclusão, Educação Infantil e Formação de Professores. Marília: Oficina Universitária; São Paulo: Cultura Acadêmica, 2013.

MENDES, E. G. Inclusão marco zero: começando pelas creches. Araraquara: Junqueira \& Marin, 2010. 303 p.

MOYLES, J. R. A excelência do brincar: a importância da brincadeira na transição entre educação infantil e anos iniciais. Artmed, 2006.

NUNES, C. Aprendizagem ativa na criança com multideficiência - guia para educadores. Coleção Apoios Educativos. Lisboa/Portugal: Ministério da Educação, 2001.

PANIAGUA, P.; PALACIOS, J. Educação Infantil - resposta educativa à diversidade. Porto Alegre: Artmed, 2007.

PEREIRA, E. T. Brincar e criança. In: CARVALHO, A et all (Orgs). Brincar (es). Belo Horizonte: Editora UFMG, 2005.

OLIVEIRA, J. B. A. Cartilhas de alfabetização: a redescoberta do código alfabético. Ensaio: avl.pol.públ. Educ. vol. 18; p. 669-710, 2010.

OLIVEIRA, Z. R. Educação Infantil: fundamentos e métodos. São Paulo: Cortez. 2002.

OLIVEIRA-FORMOSINHO, J. Contextualização do modelo curricular high/scope no âmbito do "projeto infância". In: ZABALZA, M. A. Qualidade em educação infantil. Porto Alegre: Artmed, 2007.

UNESCO. Declaração sobre educação para todos. Plano de Ação para satisfazer às necessidades básicas de aprendizagem. Jomtien: UNICEF, Brasília, 1990 (versão portuguesa).

UNESCO. Declaração de Salamanca. Sobre Princípios, Políticas e Práticas na Área das Necessidades Educativas Especiais. Salamanca, 1994.

VITALINO, C.; R. VALENTE S. M. A formação de professores reflexivos como condição necessária para inclusão de alunos com necessidades educacionais especiais. In: VITALINO, C. R. Formação de professores para a inclusão de alunos com necessidades educacionais especiais. Londrina: EDUEL, 2010. 
VITTA, F. C. F.; SILVA, C. C. B.; ZANIOLO, L. O. Educação da Criança de Zero a Três Anos e Educação Especial: uma Leitura Crítica dos Documentos que Norteiam a Educação Básica. In: Rev. Bras. Ed. Esp., Marília, v. 22, n. 1, p. 9-26, 2016.

\section{Como referenciar este artigo}

FACHINETTI, T. A.; NASCIMENTO, B. A. B. do; GIROTO, C. M. O trabalho pedagógico para alunos público-alvo da educação especial: investigando a inclusão na educação infantil. Revista Ibero-Americana de Estudos em Educação, v. 11, n. esp. 2, p.861-880, 2016. Disponível em: <https://dx.doi.org/10.21723/riaee.v11.esp2.p861880>. E-ISSN: 1982-5587.

\section{Sobre os autores}

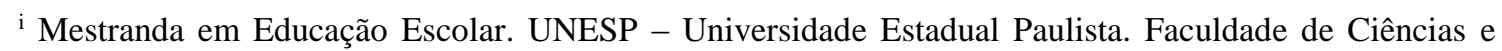
Letras - Pós-graduação em Educação Escolar. Araraquara - SP - Brasil. 14800-901 tamiris_fachinetti@hotmail.com

ii Mestranda em Educação Escolar. UNESP - Universidade Estadual Paulista. Faculdade de Ciências e Letras - Pós-graduação em Educação Escolar. Araraquara - SP - Brasil. 14800-901 bia893@hotmail.com

iii UNESP - Universidade Estadual Paulista. Faculdade de Filosofia e Ciências - Programa de PósGraduação em Educação (PPGE)/Faculdade de Filosofia e Ciências (FFC)/UNESP/Campus de Marília/SP e do PPGEE/FCLAr/Campus de Araraquara/SP - Marília - SP - Brasil. 17515-000 claudia.mosca@marilia.unesp.br 